\title{
Non-surgical endodontic management of odontogenic maxillary sinusitis
}

\author{
Lynn Lilly Varghese 다, ${ }^{1}$ Auric Bhattacharya $\quad$ 이, ${ }^{2}$ Amit Basannavar ${ }^{3}$
}

${ }^{1}$ Department of Conservative Dentistry and Endodontics, Melaka Manipal Medical College, Bukit Baru, Malaysia ${ }^{2}$ Oral and Maxillofacial Surgery, Melaka Manipal Medical College, Bukit Baru, Malaysia ${ }^{3}$ Oral and Maxillofacial Surgery, Bharati Vidyapeeth University Dental College and Hospital Sangli, Sangli, Maharashtra, India

\section{Correspondence to} Dr Lynn Lilly Varghese; lynn.varghese@manipal.edu.my

Accepted 21 May 2021

\section{DESCRIPTION}

A 28-year-old male patient presented with a broken filling on tooth 26 . The patient reported that the filling had dislodged and has been refilled multiple times previously. On further enquiry, he complained of tenderness on the left cheek, left nasal blockage and postnasal drip occurring sporadically for over a year. The patient had visited physicians and otorhinolaryngologists and has been prescribed multiple courses of antibiotics with no effect. At the time of dental visit the patient was on Augmentin $625 \mathrm{mg}$ as prescribed by the physician. He was also given the option of surgical treatment of the chronic maxillary sinusitis by the physician, but he was not interested in this course of action.

On oral examination there was a fractured disto-occlusal tooth coloured filling extending subgingivally on tooth 26 with food impaction. Tooth 26 was tender on percussion and showed no response to electric pulp test. Diagnostic periapical radiograph of tooth 26 did not show anything conclusive, so cone beam CT (CBCT) with voxel size of $150 \mu \mathrm{m}$ was advised. Threedimensional CBCT imaging increases the accuracy of detecting periapical lesions and any abnormalities of the nasal and paranasal sinuses when compared with conventional imaging modalities. ${ }^{1}$ Axial and coronal sections of the CBCT images revealed total opacification of the left maxillary sinus, as seen in figure $1 \mathrm{~A}, \mathrm{~B}$. The sagittal section of CBCT showed that the root apices of tooth 26 protruded into the maxillary sinus through a perforation in the thin cortical boundary of the maxillary sinus (figure $2 \mathrm{~A}$ ). A diagnosis of necrotic tooth 26 resulting in odontogenic maxillary sinusitis was made. A conservative and non-surgical treatment approach was considered. Thus, endodontic treatment of tooth 26 was advised.

Following administration of buccal infiltration anaesthesia and isolation with rubber dam, access

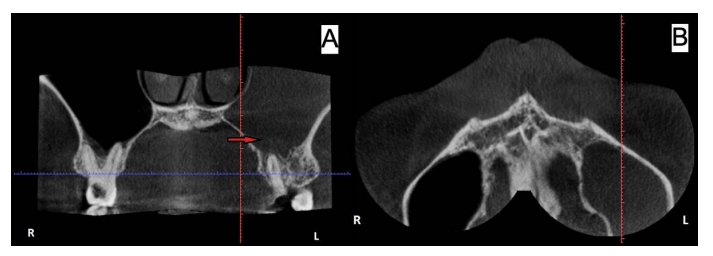

Figure $1 \quad(A, B)$ Coronal and axial sections of preoperative cone beam CT showing total opacification of the left maxillary sinus (arrow), while the right sinus appears normal. L, left; $R$, right.
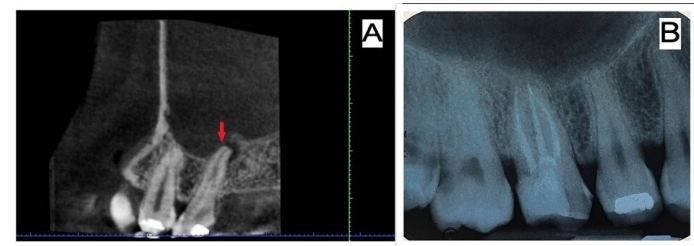

Figure 2 (A) Sagittal slice of cone beam CT showing the infected root apex of tooth 26 (arrow) encroaching into the sinus space. (B) Postobturation Intra-oral Periapical Radiograph of tooth 26.

cavity preparation was done on tooth 26. Mesiobuccal, distobuccal and palatal canals were detected. Initial working length was determined with an apex locator (Root ZX, J Morita), which was $21 \mathrm{~mm}$ in the palatal and distobuccal canals and $20 \mathrm{~mm}$ in the mesiobuccal canal. Chemomechanical preparation was completed using ProTaper and Hyflex CM rotary files (Coltene Whaledent, Altstätten, Switzerland). Irrigation during mechanical instrumentation was done using $2.5 \%$ sodium hypochlorite. Calcium hydroxide intracanal medicament was placed into the root canals and the tooth was filled temporarily with Cavit. In the next appointment after 2 weeks, irrigation was done with $2 \mathrm{~mL}$ of $17 \%$ EDTA solution, followed by a final rinse of $5 \mathrm{~mL}$ saline solution. Obturation was completed by cold lateral condensation technique using $\mathrm{AH}$ Plus sealer (figure $2 \mathrm{~B}$ ) and a composite restoration was done on tooth 26.

At 1-month follow-up appointment, the patient had complete resolution of symptoms of sinusitis and there was no discomfort in relation to the endodontically treated tooth. Following this a full

\section{Patient's perspective}

I never imagined that a visit to the dentist would result in the successful treatment of my blocked nose and sinus issues. I had gone to my dentist to get a pesky filling sorted. The dentist was very thorough in her queries and was soon to figure out why I was having repeated bouts of sinus pain, and bad phlegm in my mouth when I slept. Multiple visits to the ENT resulted in me having lots of anti-biotics and even considering surgery for my sinus issues. But a simple and painless root canal treatment fixed my sinus and dental concerns. I will always be grateful to my dentist for her patient listening and her excellent treatment. Now I believe dental treatment is not only about fixing teeth but the body also. 


\section{Learning points}

- Otorhinolaryngologists should consider dental aetiology in cases of persistent unilateral maxillary sinusitis and refer patients for further dental consultations to achieve early diagnosis and effective treatment.

- Odontogenic maxillary sinusitis is most commonly associated with infected maxillary molars due to the close anatomical proximity between root apices and sinus boundaries.

- Cone beam CT has different advantages including high contrast resolution, elimination of superimposition of anatomical structures and reduced radiation exposure compared with multislice CT and so should be considered in such cases.

coverage restoration was fabricated and placed on tooth 26 . A simple yet thorough endodontic treatment was able to sort the patient's dental as well as sinus issues which have been troubling him for over a year. This case thus enforces and highlights to the clinician the importance of eliciting proper case history and using appropriate investigative tools such as CBCT. Similar treatment outcomes have been achieved in various case reports in the literature using non-surgical endodontics. ${ }^{2} 3$ Thus following this protocol will contribute to accurate diagnosis and treatment, which will provide swift relief to patients.

Contributors LLV was responsible for diagnosis and treatment of the case. $A B$ was involved in treatment planning and follow-up of the manuscript. $A B$ was involved in drafting of the manuscript.

Funding The authors have not declared a specific grant for this research from any funding agency in the public, commercial or not-for-profit sectors.

Competing interests None declared.

Patient consent for publication Obtained.

Provenance and peer review Not commissioned; externally peer reviewed.

\section{ORCID iDs}

Lynn Lilly Varghese http://orcid.org/0000-0002-7490-9984

Auric Bhattacharya http://orcid.org/0000-0002-0108-327X

\section{REFERENCES}

1 Lofthag-Hansen S, Huumonen S, Gröndahl K, et al. Limited cone-beam CT and intraoral radiography for the diagnosis of periapical pathology. Oral Surg Oral Med Oral Pathol Oral Radiol Endod 2007;103:114-9.

2 Teixeira LEP, Lângaro MC, Hartmann MSM. Acute odontogenic maxillary sinusitis treated endodontically - two case reports and 15-day CBCT outcome. Braz J Oral Sci 2018;17:e181197.

3 Bogaerts P, Hanssens JF, Siquet JP. Healing of maxillary sinusitis of odontogenic origin following conservative endodontic retreatment: case reports. Acta Otorhinolaryngol Belg 2003;57:91-7.

Copyright 2021 BMJ Publishing Group. All rights reserved. For permission to reuse any of this content visit

https://www.bmj.com/company/products-services/rights-and-licensing/permissions/

BMJ Case Report Fellows may re-use this article for personal use and teaching without any further permission.

Become a Fellow of BMJ Case Reports today and you can:

- Submit as many cases as you like

- Enjoy fast sympathetic peer review and rapid publication of accepted articles

- Access all the published articles

- Re-use any of the published material for personal use and teaching without further permission

\section{Customer Service}

If you have any further queries about your subscription, please contact our customer services team on +44 (0) 2071111105 or via email at support@bmj.com.

Visit casereports.bmj.com for more articles like this and to become a Fellow 